\title{
The Impact of Interest Rate Marketization on China's Commercial Banks and Its Tactics
}

\author{
Xinrong Cui \\ School of Economics, Jinan University, Guangzhou, China \\ Email: xrstjk@163.com
}

How to cite this paper: Cui, X.R. (2016) The Impact of Interest Rate Marketization on China's Commercial Banks and Its Tactics. Journal of Mathematical Finance, 6, 921-929. http://dx.doi.org/10.4236/jmf.2016.65061

Received: October 24, 2016

Accepted: November 21, 2016

Published: November 24, 2016

Copyright $\odot 2016$ by author and Scientific Research Publishing Inc. This work is licensed under the Creative Commons Attribution International License (CC BY 4.0).

http://creativecommons.org/licenses/by/4.0/

\begin{abstract}
With the advance of market-oriented interest rate, the risk of commercial banks in our country is increasing day by day, including credit risk and interest rate risk. This paper mainly discusses the interest rate risk, and the re-pricing risk based on the interest rate risk. And this paper makes an empirical study and puts forward countermeasures of the commercial banks in China under the background of marketoriented interest rate.
\end{abstract}

\section{Keywords}

Interest Rate Marketization, Interest Rate Risk

\section{An Overview of Market-Oriented Interest Rate}

The market-oriented interest rate is the market choice after eliminating the interest rate regulation in the process of financial reform. Its fundamental purpose is to play the core role of interest rate in capital allocation. Specifically, the market-oriented interest rate means that the central bank gives the interest rate decision to the market, and the market spontaneously determines the interest rate, but the central bank can still control and guide market interest rate through deposit reserve system, rediscount, open market operation and other monetary policy instruments so that the market mechanism plays a leading role in capital allocation.

In China, with the continuous development of market economy, the deepening of the financial system reform and the gradual integration with the international market, the drawbacks of the original interest rate control began to emerge, resulting in economic inefficiency and imbalance, economic inefficiency and imbalance in turn restricts the further development of the economy. Interest rate control has gradually become China's economic and financial reform in the "bottleneck". In order to maintain sustained 
and healthy economic development, it is necessary to improve the investment structure and improve the efficiency of investment. The market-oriented interest rate reform has become a necessity.

\section{The Impact of Market-Oriented Interest Rate on Commercial Banks in China}

\subsection{The Increased Credit Risk}

Credit risk is the risk that the bank's business will be lost, arising from the borrower or counterparty failing to fulfill their obligations in accordance with the contract. With the advancement of market-oriented interest rate, interest rate regulation began to loosen. And commercial banks can attract customers by raising deposit rates, but which will increase their financing costs. In order to maintain their returns, banks will raise interest rates on loans, but the borrower who are willing to pay high interest rates are poor operating performance and the lack of credibility in the market, this is called "adverse selection". When enterprises are forced to engage in high-risk projects under the high interest rate, the credit risk of commercial banks also increases [1].

\subsection{The Increased Interest Rate Risk}

\subsubsection{The Concept of Interest Rate Risk}

Interest rate risk refers to the risk that the bank's overall income and economic value will be lost, arising from unfavorable changes in the interest rate and maturity structure. After the market-oriented interest rate, the volatility of interest rate will be strengthened, and the forecast of its fluctuation trend will be more difficult, and the interest rate risk will increase.

\subsubsection{Classification of Interest Rate Risk}

Based on the definition of interest rate risk, this paper divides interest rate risk into four categories: re-pricing risk, base risk, implicit option risk and yield curve risk [2].

\section{1) Re-pricing Risk}

Re-pricing risk is the risk that arises from term mismatch of the bank assets and debts that the interest rate sensitive assets (ISA) and interest rate sensitive liabilities (ISL) do not match in the total amount or term structure. Interest rate sensitive assets (ISA) refers to the asset that the yield will fluctuate with the change of market interest rates, such as maturing loans, short-term loans etc. Interest rate sensitive liabilities (ISL) refers to the liability that interest payments will fluctuate with the change of market interest rates, such as demand deposits, variable-rate deposits etc. The difference of interest rate sensitive assets (ISA) and interest-sensitive liabilities (ISL) is the interest rate sensitivity gap (GAP). The greater the GAP is, the greater the volatility of interest rates is and the greater the risk is.

\section{2) Basis Risk}

Commercial banks usually set their deposit and loan rates according to certain benchmark interest rate. But when the deposit and loan interest rates are asymmetric, 
the interest space of commercial banks will be squeezed, thus forming basis risk.

\section{3) Yield Curve Risk}

The yield curve risk is also called interest rate term structure change risk, which arises from the abnormal form of the yield curve. In general, the slope of the yield curve is positive, which indicates that the long-term interest rate is higher than the short-term interest rate. But sometimes the slope of the yield curve may be zero or even negative, indicating that the long-term interest rate equal to or even less than short-term interest rates, then commercial banks will face the risk curve.

\section{4) Selective Risk}

The selective risk is an implicit option, and the buyer have the right to enforce or give up the right, and the seller (commercial banks) will face the risk. In the daily business of commercial banks, the implicit option exists in many deposit and loan contracts. For example, when the interest rate drops, the borrower will choose to execute the implicit option (prepayment) to avoid the risk, then commercial banks will suffer interest losses.

\subsubsection{Interest Rate Risk Measurement}

\section{1) Interest Rate Sensitivity Gap Analysis}

Interest rate sensitivity analysis is widely used in China's commercial banks; there are absolute and relative values of the two measures. The absolute value index is the interest sensitivity gap (GAP) mentioned above, and the relative value is the ratio of interest rate sensitive assets (ISA) to interest rate sensitive liabilities (ISL), namely interest rate sensitivity ratio (RSR), and the specific relationship between them is shown in Table 1 .

Because the interest rate gap method only measures the risk of re-pricing, and it requires the same time period for all positions, so it has some limitations.

\section{2) Duration Gap Analysis}

Duration, also known as nine, was first proposed by Macquarie, and therefore also known as Macaulay Duration (D), which measures the average time that it takes to repay the debt.

$$
D=\frac{\sum_{t=1}^{n} P V_{t}}{P_{0}} \times t=\frac{\sum_{t=1}^{n} P V_{t}}{\sum_{t=1}^{n}\left[P V_{t} /(1+r)^{t}\right]}
$$

Table 1. Interest rate sensitivity index.

\begin{tabular}{cccc}
\hline $\begin{array}{c}\text { Interest rate sensitivity } \\
\text { gap (GAP) }\end{array}$ & $\begin{array}{c}\text { Interest rate sensitivity } \\
\text { ratio (RSR) }\end{array}$ & $\begin{array}{c}\text { The change of } \\
\text { interest rate }\end{array}$ & $\begin{array}{c}\text { Net interest income } \\
\text { Variety }\end{array}$ \\
\hline Positive gap & $>1$ & rise & increase \\
& & decline & decrease \\
Negative gap & $<1$ & rise & decrease \\
& & decline & increase \\
0 & $=1$ & rise & constant \\
& & decline & constant \\
\hline
\end{tabular}


Note:

$D$ : Macaulay Duration.

$P V_{\dot{t}}$ The present value of the cash flow in period $t$.

$r$. Yield to maturity.

$P_{0}$ : The prices of assets and liabilities.

When the cash flow is susceptible to changes in interest rates, the Macquarie Duration is no longer applicable, and a modified duration is used, which reflects the percentage change in bond price per unit interest rate change. Let $D^{*}=D /(1+r)$, therefore $d p / p=-D^{*} \times \Delta r$, and the modified duration is $D^{*}=-d p / p / \Delta r$.

For a bank's assets and liabilities, the duration can be understood as the average duration of its assets or liabilities. In general, the longer the duration, the more sensitive the price to the interest rate, the greater the interest rate risk [3]. A bank can use the duration gap to measure the interest rate risk of its assets and liabilities, duration gap = weighted average duration of assets - (total liabilities/total assets) $\times$ liabilities weighted average duration. When the duration gap is not zero, it indicates that the same change of interest rate will cause different changes of assets and liabilities, thus bringing the risk to the bank. The higher the absolute value of the duration gap, the higher the risk of interest rate fluctuation.

Duration gap method is a dynamic analysis which mainly use the present value of cash flow, and it makes up for the shortcomings of interest rate sensitivity gap method to some extent. But it only considered the re-pricing risk, and it is more difficult to calculate for the duration of the value may change with the interest rate.

\section{3) VaR Model}

$\mathrm{VaR}$ is the value of $\mathrm{VaR}$, which means the maximum loss that a portfolio can suffer under certain confidence level when the market interest rate changes. The method is divided into nonparametric method (historical simulation method and Monte Carlo simulation method) (Variance-covariance method and GARCH family model), semiparametric method three, and we don't talk about them in detail. The VaR model whose calculation standard is uniform is simple and clear in measuring the risk, and the risk can be estimated in advance. But in terms of the data processing, there must be enough historical data and we also need to taking into account the validity of the data.

\section{4) Scenario Analysis and Stress Testing}

Scenario analysis is based on a variety of assumptions about the evolution of economy, industry or technology, to imagine various possible programs of the future by detailed, rigorous reasoning and description about the future. Stress testing is to study how the risk factor will change and whether the change will cause the loss of the bank when a portfolio is placed in a particular extreme market.

\section{Empirical Research of Commercial Banks Interest Rate Risk Management}

\subsection{Model Selection and Data Sources}

This paper chooses nine commercial banks, including three state-owned commercial 
banks (ICBC, CCB, BC), three joint-stock commercial banks (CITIC Bank, SPD Bank, China Merchants Bank) and three city commercial banks (Bank of Beijing, Bank of Nanjing, Bank of Ningbo), to study the re-pricing risk using the interest-sensitivity gap model. The reason for the election of the nine banks is that they can represent the current China's banking sector, and the data are easier to obtain for they have been listed. The interest rate data was selected from February 9, 2011 to October 24, 2015, because it included interest rate declines from July 2011 to October 2015 and, accordingly, In this paper, the data of interest-sensitive assets and liabilities of nine banks from December 31, 2011 to December 31, 2014 are selected to study the relationship between interest rate risk and interest rate risk. Interest-sensitive assets and liabilities come from the annual reports of the banks, which can be used to calculate each index of interest rate sensitivity gap model.

\subsection{Data Processing and Calculation}

In view of the different scale of state-owned banks, joint-stock companies and city commercial banks, we use relative indicators-interest rate sensitivity ratio (RSR) and interest rate sensitivity deviation to measure interest rate risk.

1) Interest Rate Sensitivity Ratio (RSR) = Interest Rate Sensitive Asset (ISA)/ Interest Rate Sensitive Liability (ISL)

The closer the RSR is to 1, the lower the interest rate risk. For banks seeking profits, the RSR indicator should be greater than 1 (positive gap) in the rate hike cycle and less than 1 (negative gap) in the rate cut cycle. This paper divides the interest-sensitive assets and liabilities into short-term and long-term, and then calculates the short-term and long-term interest rate sensitivity ratios respectively.

2) Interest Rate Sensitivity Ratio Deviation = Interest Rate Sensitivity Ratio (RSR) - 1

Interest Rate Sensitivity Ratio Deviation is the deviation of interest rate sensitivity ratio from parameter 1 . The smaller the absolute value of the deviation, the less affected the fluctuation of the interest rate.

\subsection{The Analysis and Comparison of Data}

Since interest rate risk is caused by changes in interest rates, we need to observe the changes in interest rates. As shown in Figure 1, between 2011 and 2015, deposit and lending rates are rising before July 2011, and then in decline. Combining Table 2, the following analysis results are obtained.

After the interest rate cut started in July 2011, the net interest rates of all the nine commercial banks except CCB, CITIC Bank, China Merchants Bank and Shanghai Pudong Development Bank, the short-term interest rate sensitivity ratios of the other five commercial banks were less than 1 (negative gap) and whose net interest are increase. Among them, the short-term RSR of China Construction Bank, China Merchants Bank and Shanghai Pudong Development Bank are greater than 1 (positive gap), but the degree of deviation is relatively small. Therefore, the interest loss is not too much, and 


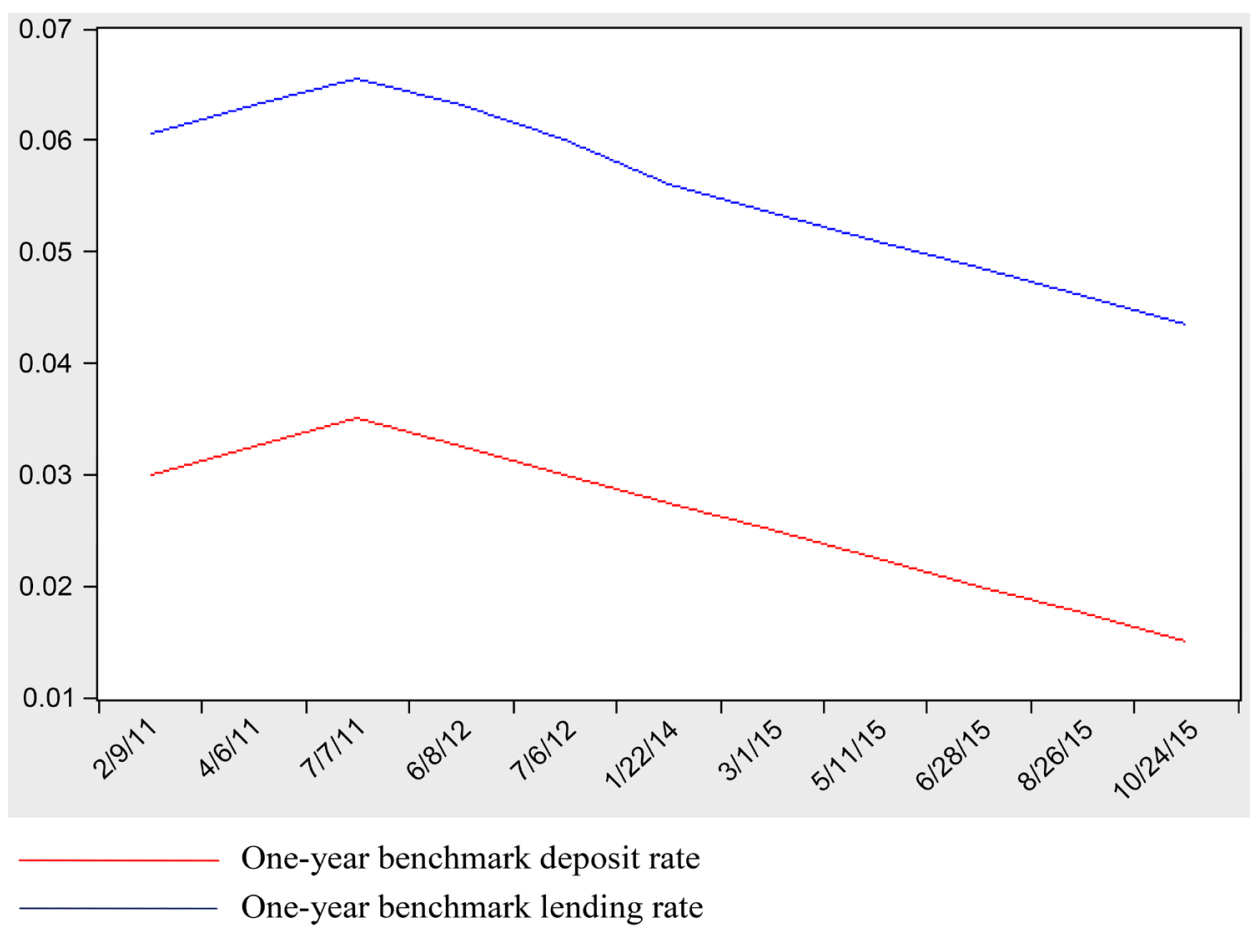

Source: People's Bank of China

Figure 1. The trends of one-year deposit and lending benchmark interest rate in 2011-2015.

Table 2. Statistical tables of interest rate sensitivity ratio and degree of deviation of nine commercial banks in 2011-2014 (Negative values in parentheses, DOD represent the degree of deviation, $\mathrm{S}$ represent short and $\mathrm{L}$ represent Medium and long term).

\begin{tabular}{cccccccccc}
\hline \multirow{2}{*}{ Unit: RMB million } & & \multicolumn{2}{c}{ 2011-12-31 } & \multicolumn{2}{c}{ 2012-12-31 } & \multicolumn{2}{c}{ 2013-12-31 } & \multicolumn{2}{c}{ 2014-12-31 } \\
\cline { 2 - 10 } ICBC & S & 0.93 & $(0.07)$ & 0.99 & $(0.01)$ & 0.97 & $(0.03)$ & 1.01 & 0.01 \\
& L & 2.37 & 1.37 & 1.63 & 0.63 & 1.82 & 0.82 & 1.61 & 0.61 \\
CCB & S & 1.02 & 0.02 & 1.01 & 0.01 & 1.03 & 0.03 & 1.00 & 0.00 \\
& L & 2.41 & 1.41 & 1.65 & 0.65 & 1.97 & 0.97 & 1.74 & 0.74 \\
BC & S & 0.67 & $(0.33)$ & 1.03 & 0.03 & 1.02 & 0.02 & 1.03 & 0.03 \\
CITIC BANK & L & 4.36 & 3.36 & 1.30 & 0.30 & 1.14 & 0.14 & 1.17 & 0.17 \\
SPD BANK & S & 1.08 & 0.08 & 1.08 & 0.08 & 1.07 & 0.07 & 1.03 & 0.03 \\
& L & 0.80 & $(0.20)$ & 0.96 & $(0.04)$ & 0.99 & $(0.01)$ & 1.43 & 0.43 \\
& S & 1.03 & 0.03 & 1.04 & 0.04 & 0.99 & $(0.01)$ & 1.00 & 0.00 \\
China Merchants Bank & L & 1.40 & 0.40 & 1.22 & 0.22 & 1.78 & 0.78 & 1.78 & 0.78 \\
& S & 1.03 & 0.03 & 1.04 & 0.04 & 1.03 & 0.03 & 0.97 & $(0.03)$ \\
& L & 1.89 & 0.89 & 1.52 & 0.52 & 1.89 & 0.89 & 2.00 & 1.00 \\
Bank of Beijing & S & 0.99 & $(0.01)$ & 0.98 & $(0.02)$ & 0.96 & $(0.04)$ & 0.93 & $(0.07)$ \\
& L & 1.73 & 0.73 & 1.93 & 0.93 & 2.50 & 1.50 & 2.72 & 1.72 \\
Bank of Nanjing & S & 0.97 & $(0.03)$ & 1.00 & 0.00 & 0.91 & $(0.09)$ & 0.80 & $(0.20)$ \\
& L & 2.22 & 1.22 & 1.66 & 0.66 & 2.00 & 1.00 & 3.06 & 2.06 \\
Bank of Ningbo & S & 0.99 & $(0.01)$ & 0.95 & $(0.05)$ & 0.96 & $(0.04)$ & 0.95 & $(0.05)$ \\
& L & 2.23 & 1.23 & 1.85 & 0.85 & 1.06 & 0.06 & 1.82 & 0.82 \\
\hline
\end{tabular}

Source: Calculated from the data that be showed in the annual report of the banks and the initial detailed data comes from wind financial terminal. 
CITIC Bank's deviation is relatively large, which shows that it cannot adjust the type of gap flexibility to response to the interest rate risk [4].

In 2012-2014, the interest rates fall into the downtrend, we can find that the shortterm RSR of urban commercial banks is less than 1 (RSR = 1 in 2012 in Nanjing), and the degree of deviation has a tendency to increase with time, but these changes in the degree of deviation conducive to the increase in net interest. The three joint-stock banks have begun to adjust slowly, and their short-term RSR deviation gradually reduced, Shanghai Pudong Development Bank and China Merchants Bank adjusted to a negative gap in 2013, 2014. In the state-owned banks, ICBC continued to maintain a negative gap, but it arises positioning error on the shortfall of the gap type in 2014, and this can be seen from where short-term RSR $>1$, while the degree of deviation is small; CCB continued to keep positive gap ( $R S R>1)$, But the gap is 0 in 2014 (RSR = 1), earnings are not affected by changes in interest rates; Bank of China had a negative gap in 2011, but it adjusted to positive gap in 2012, and in the next three years, gap Type targeting error continued. Overall, the interest rate risk management capability of stateowned banks is weaker than that of small and medium-sized commercial banks.

In the medium and long term, in addition to CITIC Bank in 2011-2013 to maintain a negative gap, the other banks have continued to maintain a positive gap, most banks long-term RSR deviation has remained positive and high, indicating that the medium and long term asset-liability structure of the bank is unreasonable, and they will face a great interest rate risk in the interest rate cut trend.

\section{The Countermeasures of Commercial Banks under the Marketization of Interest Rate}

\subsection{Adjust the Business Structure}

\subsubsection{Vigorously Develop the Intermediary Business}

Under the condition of marketization of interest rate, the margin gaining by the difference between the deposit and loan interest rate will decrease, and the bank will suffer a great impact. Therefore, the commercial banks should actively carry out diversified business, reduce the reliance on the deposit and loan spreads. On the one hand, it is necessary to continuously expand the scope of intermediary business, focusing on the development of financial consultants, insurance agents and other intermediary business, and gradually carry out asset management, credit guarantee, commitment and other high value-added intermediary business; on the other hand, make full use of the banking system data resources by the large data analysis technology, and obtain customer preferences to optimize customer experience.

\subsubsection{Optimize the Customer Structure}

After the marketization of interest rate, customers' choice of financial institutions is expanding and some of them have a good operating performance and high credit, so they can choose the loan source according to the loan price of each bank. Therefore, the bank should change the operation model that only provide loan service for large enterprises 
and actively enter the SME market, optimize customer structure to increase profits.

\subsection{To Promote Financial Product Innovation}

The marketization of interest rate is the process of gradual relaxation of regulation. Banks can transform more traditional liabilities business into other financial instruments which can bring middle business income by innovating various types of debt substitute products such as wealth management products, funds and government bonds. Under the precondition of controlling risks, banks should actively develop interest rate derivatives that can meet the needs of various market segments, tap potential customers and enhance profitability.

\subsection{To Improve Pricing Management Capabilities}

Under the condition of marketization of interest rate, many commercial banks participate in market competition and jointly determine the level of interest rate. Proper and reasonable pricing of funds will be an important factor in determining the competitiveness of banks. Pricing, on the one hand, should fully consider the factors that affect the pricing of funds, and according to the principle of the risk and return to match to determine the risk premium and the interest rate pricing model, also the net interest margin should be sufficient to cover the cost and target rate of return on capital; on the other hand, banks can use the statistical analysis software to make differentiated price according to the customer's characteristics of saving propensity and payment preference. And comprehensive contribution evaluation model which establish classification criteria according to the customer's contribution can be built if necessary, by this we can achieve both the efficiency and effectiveness of pricing [5].

\subsection{To Strengthen Asset and Liability Management Capabilities}

In the asset business, we will gradually develop the retail loan business, design different product according to different customer groups; adjust the income structure, reduce the proportion of loans in the assets, enhance non-interest income. In terms of liabilities, the Company strengthened its active debt management, controlled the growth of high-cost liabilities, and made full use of the inter-bank borrowing market [6].

\subsection{To Strengthen Risk Management Capabilities}

Improve the internal credit rating system and strengthen the credit risk control; actively use the sensitivity of the gap, the duration of the use of the risk management system to improve the risk management system, to accurately identify and assess the risk, based on the flexible use of hedging, futures options and other financial derivatives to avoid risks; Gap, stress testing and other risk measurement methods to measure the risk of the Bank, the use of risk hedging technology hedge interest rate risk.

\section{Conclusion}

This paper mainly introduces the impact of interest rate marketization on bank credit 
risk and interest rate risk, and selects nine sample firms which can represent the banking industry in our country. We use the sensitivity gap analysis to study the interest rate risk, and find that under interest rate marketization, the banking industry's structure of medium and long-term assets and liabilities is unreasonable, and the interest rate risk management ability of state-owned banks is weaker than that of small and mediumsized commercial banks. Finally, the bank's response strategy is put forward.

\section{References}

[1] Zhang, D.H., Zhu, T.X. and Xu, M.S. (2012) Study on the Impact of Interest Rate Marketization on Commercial Banks. Financial Perspectives Journal.

[2] Feng, E.Y. (2013) Interest rate Marketization of China's Commercial Banks Interest Rate Risk Research. Master's Degree Thesis, Southwest University of Finance \& Economics, Chengdu.

[3] Saree (2015) A Comparative Study of Commercial Banks' Risk Management Based on Interest-Sensitivity Gap Model. Master Thesis, Zhejiang University, Hangzhou .

[4] Li, C.H. and Dong, X.L. (2012) The Empirical Research on the Interest Rate Risk Management of Chinese Commercial Banks. East China Economic Management, 26, 88-92.

[5] Li, H.J. (2015) The Challenge of Interest Rate Marketization to Commercial Banks and the Corresponding Tactics. Studies of International Finance, No. 2, 65-76.

[6] Yu, D.Z., Guo, N. and Guan, J.C. (2012) Study on Assets and Liabilities Management of China’s Commercial Banks under Interest Rate Marketization. Rural Finance Research, No. 9, 37-41. for you:

Accepting pre-submission inquiries through Email, Facebook, LinkedIn, Twitter, etc. A wide selection of journals (inclusive of 9 subjects, more than 200 journals)

Providing 24-hour high-quality service

User-friendly online submission system

Fair and swift peer-review system

Efficient typesetting and proofreading procedure

Display of the result of downloads and visits, as well as the number of cited articles

Maximum dissemination of your research work

Submit your manuscript at: http://papersubmission.scirp.org/

Or contact jmf@scirp.org 